\title{
Nest box design for the study of diurnal raptors and owls is still an overlooked point in ecological, evolutionary and conservation studies: a review
}

\author{
Marcel M. Lambrechts $\cdot$ Karen L. Wiebe $\cdot$ Peter Sunde $\cdot$ Tapio Solonen $\cdot$ Fabrizio Sergio • \\ Alexandre Roulin - Anders Pape Møller • Bernat C. López · Juan A. Fargallo • Klaus-Michael Exo • \\ Giacomo Dell'Omo · David Costantini $\cdot$ Motti Charter $\cdot$ Michael W. Butler · Gary R. Bortolotti • \\ Raphaël Arlettaz $\cdot$ Erkki Korpimäki
}

Received: 10 March 2011/Revised: 13 May 2011/ Accepted: 1 June 2011/Published online: 15 June 2011

(c) Dt. Ornithologen-Gesellschaft e.V. 2011

\begin{abstract}
The use of artificial nest boxes has led to significant progress in bird conservation and in our understanding of the functional and evolutionary ecology of free-ranging birds that exploit cavities for roosting and reproduction. Nest boxes and their improved accessibility have made it easier to perform comparative and
\end{abstract}

Communicated by F. Bairlein.

M. M. Lambrechts ( $\square)$

Centre d'Ecologie Fonctionnelle et Evolutive, UMR 5175,

CNRS, 1919 route de Mende, 34293 Montpellier Cedex 5,

France

e-mail: marcel.lambrechts@cefe.cnrs.fr

E. Korpimäki

Section of Ecology, Department of Biology,

University of Turku, 20014 Turku, Finland

e-mail: ekorpi@utu.fi

\section{R. Arlettaz}

Division Conservation Biology, Institute of Ecology and Evolution, University of Bern, 3012 Bern, Switzerland e-mail: raphael.arlettaz@iee.unibe.ch

\section{R. Arlettaz}

Valais Field Station, Swiss Ornithological Institute,

3960 Salgesch, Switzerland

K. L. Wiebe - G. R. Bortolotti

Department of Biology, University of Saskatchewan,

112 Science Place, Saskatoon, SK S7N 5E2,

Canada

e-mail: gary.bortolotti@usask.ca

\section{P. Sunde}

Department of Wildlife Ecology and Biodiversity, National Environmental Research Institute, Aarhus University,

Grenåvej 14, 8410 Rønde, Denmark

e-mail: psu@dmu.dk experimental field investigations. However, concerns about the generality and applicability of scientific studies involving birds breeding in nest boxes have been raised because the occupants of boxes may differ from conspecifics occupying other nest sites. Here, we review the existing evidence demonstrating the importance of nest box design to individual life-history traits in three falcon (Falconiformes) and seven owl (Strigiformes) species, as well

M. W. Butler

School of Life Sciences, Arizona State University, Tempe,

AZ 85287-4601, USA

e-mail: Mike.Butler@asu.edu

\section{T. Solonen}

Luontotutkimus Solonen Oy, Neitsytsaarentie 7b B 147,

00960 Helsinki, Finland

e-mail: tapio.solonen@pp.inet.fi

M. Charter

George S. Wise Faculty of Life Sciences,

Department of Zoology, Tel Aviv University,

69978 Ramat Aviv, Tel Aviv, Israel

e-mail: MottiC@tauex.tau.ac.il

F. Sergio

Estacion Biologica de Doñana, CSIC, C/Americo Vespucio, s/n, 41092 Sevilla, Spain

e-mail: fsergio@ebd.csic.es

D. Costantini

School of Life Sciences, Institute of Biodiversity,

Animal Health and Comparative Medicine,

University of Glasgow, Glasgow, UK

e-mail: David.Costantini@glasgow.ac.uk

A. Roulin

Department of Ecology and Evolution, Biophore,

University of Lausanne, 1015 Lausanne, Switzerland

e-mail: Alexandre.Roulin@unil.ch 
as the extent to which publications on these birds describe the characteristics of exploited artificial nest boxes in their "Methods" sections. More than $60 \%$ of recent publications did not provide any details on nest box design (e.g. size, shape, material), despite several calls $>15$ years ago to increase the reporting of such information. We exemplify and discuss how variation in nest box characteristics can affect or confound conclusions from nest box studies and conclude that it is of overall importance to present details of nest box characteristics in scientific publications.

Keywords Falcons - Nest boxes - Owls - Raptors · Secondary cavity-nesting birds

Zusammenfassung Durch den Einsatz künstlicher Nisthilfen konnten im Vogelschutz große Erfolge erzielt werden. Darüber hinaus ermöglichte der vereinfachte Zugang zu Nestern und Altvögeln eine Vielzahl vergleichender und experimenteller Feldstudien, so dass funktionelle Zusammenhänge wie auch evolutionsbiologische Aspekte im Freiland bearbeitet werden konnten. Auf der anderen Seite wurden aber auch immer wieder Zweifel geäußert, ob und inwieweit sich an NistkastenPopulationen gewonnene Daten verallgemeinern lassen. Nistkastenbrüter bzw. eine Vielzahl verschiedener biologischer Parameter können sich in vielfacher Weise von in Naturnestern brütenden Vögeln unterscheiden. Aufbauend auf einer umfangreichen Literaturrecherche wird am

\section{G. Dell'Omo}

Ornis Italica, Piazza Crati 15, 0099 Rome, Italy

e-mail: giacomo.dellomo@gmail.com

\section{A. P. Møller}

Laboratoire Ecologie, Systématique et Evolution, UMR 8079, CNRS-Université Paris-Sud XI-AgroParisTech, Bâtiment 362, Université Paris-Sud XI, 91405 Orsay, Cedex, France

e-mail: anders.moller@u-psud.fr

\section{K.-M. Exo}

Institute of Avian Research "Vogelwarte Helgoland", An der Vogelwarte 21, 26386 Wilhelmshaven, Germany

e-mail: michael.exo@ifv-vogelwarte.de

B. C. López

CREAF, Unitat d'Ecologia (BABVE), Universitat Autònoma de Barcelona, Edifici C (Facultat de BioCiències),

08193 Bellaterra, Catalunya, Spain

e-mail: bernat.claramunt@uab.cat

B. C. López

LUTRA Environmental Association,

25721 Bellver de Cerdanya, Catalunya, Spain

\section{J. A. Fargallo}

Department Ecology and Evolution, Museo Nacional de

Ciencias Naturales, CSIC, Madrid, Spain

e-mail: fargallo@mncn.csic.es
Beispiel von drei Greifvogel- (Falconiformes) und sieben Eulenarten (Strigiformes) der Einfluss des Nistkastendesigns auf individuelle life history traits untersucht. Zugleich wurde analysiert, ob und inwieweit die Charakteristika der genutzten Nistkästen im Methodenkapitel der Publikationen angeführt wurden. Obwohl bereits vor über 15 Jahren mehrfach darauf hingewiesen wurde, dass Details zu den verwendeten Nistkästen beschrieben werden sollten, fanden sich in über $60 \%$ der aktuellen Publikationen keinerlei Angaben bspw. zu Größe, Form oder auch dem Material der Kästen. Anhand ausgewählter Beispiele wird der Einfluss verschiedener Nistkastencharakteristika auf verschiedene Parameter, bspw. die Gelegestärke, den Bruterfolg, die Belastung mit Parasiten, Interaktionen zwischen Arten etc., dargestellt und diskutiert. Deutlich wird, dass es in wissenschaftlichen Publikationen unerlässlich ist, die eingesetzten Nisthilfen detailliert zu beschreiben.

\section{Introduction}

Many secondary cavity-nesting animals (vertebrates, invertebrates) that exploit natural cavities for roosting or breeding also use holes in buildings, or occupy human-made constructions (e.g. artificial stick nests, nest boxes) attached to tree trunks, fences, walls, utility poles, or posts. This is also the case for secondary cavity-nesting members of the Falconiformes and Strigiformes orders (Village 1983; Korpimäki 1984; Toland and Elder 1987; Schönn et al. 1991; Bortolotti 1994; Doody 1994; Gehlbach 1994a, b; Pomarol 1996; Valkama and Korpimäki 1999; Sullivan et al. 2003; Franco et al. 2005; Beasley and Parrish 2009; Steenhof and Peterson 2009; Charter et al. 2007; van Nieuwenhuyse et al. 2008; Costantini et al. 2009; López et al. 2010; Riegert et al. 2010). Nest boxes are artificial cavities that have been designed to attract secondary cavity-nesters for roosting or breeding. The widespread use of nest boxes can halt population declines or can considerably increase a local population, especially in environments where cavity-forming trees are missing or abandoned buildings have become unavailable (Hamerstrom and Hamerstrom 1973; Arlettaz et al. 1991; Schönn et al. 1991; Exo 1992; Solonen 1993; Johnson 1994; Newton 1994; Petty et al. 1994; Ravussin et al. 2001; Lõhmus 2003; Meyrom et al. 2009; Arlettaz et al. 2010; but see Klein et al. 2007).

The use of nest boxes has also advanced the understanding of functional and evolutionary aspects of life-history traits in local populations. Nest boxes can facilitate access to nest cavities and their contents, and therefore allow routine monitoring and handling of eggs or nestlings, as well as repeated trapping, identifying and 
sampling nesting birds or their offspring (Korpimäki 1987a, b, 1988a, b, 1993; Schönn et al. 1991; Exo 1992; Tella et al. 2000; Brommer et al. 2003; Smallwood et al. 2009). Using nest boxes as tools may also help to better control stochastic influences associated with abiotic factors, conspecifics or heterospecifics, thus increasing sample sizes for monitoring and scientific research, but at the cost of missing information on such stochastic influences that constitute an important area of research in modern ecology (Koenig et al. 1992; Møller 1989, 1992, 1994). For instance, comparative and experimental research has been facilitated in the fields of behavioural, environmental, evolutionary, demographic and conservational sciences when populations or species rapidly accept artificial nest boxes for reproduction (Korpimäki 1984; Clutton-Brock 1988; Newton 1989; Sonerud 1989; Dijkstra et al. 1990; Gard and Bird 1990; Exo 1992; Wiehn and Korpimäki 1997, 1998; Roulin et al. 1998; Fargallo et al. 2001; Bortolotti et al. 2002; Laaksonen et al. 2004; Klein et al. 2007; Butler et al. 2009; Santolo and Yamamoto 2009; Smallwood et al. 2009; Arlettaz et al. 2010; Charter et al. 2010a; but see Kirk and Hyslop 1998 for difficulties of large-scale monitoring). Nest boxes have also been erected for control of rodents by farmers (Duckett 1991; Meyrom et al. 2009; but see Valkama et al. 2005).

Møller (1989, 1992), and Koenig et al. (1992) discussed in detail the potential artefacts associated with the use of nest boxes in birds and advised field researchers to (1) ameliorate the design of nest boxes aimed to attract secondary cavity-nesters so that they mimic more closely the characteristics of natural or preferred nesting sites, and (2) describe in detail the characteristics of their boxes and the procedures used for maintaining boxes to allow for the exact replication of protocols across studies (see also Kelly 2006). A symposium on falcons and owls organised by Gehlbach (1994a; coordinator) subsequently concluded that nest boxes were adequate substitutes for natural cavities and that information gathered on population size and productivity was unbiased. However, because new data show some significant effects of box characteristics on lifehistory traits in avian species, including members of the Strigiformes and Falconiformes, we believe that Møller's $(1989,1992)$ and Koenig et al.'s (1992) recommendations are still relevant, and that it is important to assess whether subsequent studies have improved their reporting and justification of the design and placement of boxes. Therefore, we first review the existing evidence demonstrating the importance of nest box design to individual life-history traits in free-ranging falcons and owls, and secondly verify the extent to which publications on these birds describe the characteristics of exploited artificial nest boxes in their "Methods" sections.

\section{Effects of nest types on life-history parameters in free-ranging populations}

Differences between nest boxes and other nest sites

Concerns about the generality and applicability of studies involving birds breeding in nest boxes have been raised because the occupants of boxes may differ from conspecifics occupying other nest types (Korpimäki 1984; Møller 1989, 1992, 1994; Hayward et al. 1992; Petty et al. 1994; Charter et al. 2007; van Nieuwenhuyse et al. 2008; Lambrechts et al. 2010). Research results are likely to be influenced by the tools used (e.g. nest boxes vs. other nest sites), the choice of model species (those that can be investigated more easily), and/or logistics (nest accessibility to human observers). The validity of ecological and evolutionary conclusions from data gathered using nest boxes is difficult to assess because the performance of pairs that occupy nest boxes is rarely compared to pairs that use other nest types at the same location following appropriate sampling designs (Hurlbert 1984; Hairston 1989). In principle, potential biases can be evaluated by examining whether the characteristics of artificial nest boxes and their occupants differ from those of other nest types, and whether any such differences would affect the likelihood of supporting or rejecting the hypotheses to be tested. Hayward et al. (1992), for instance, discussed in detail the potential sampling biases that may exist between owls occupying nest boxes and the target population occupying other nest types.

Although several field studies on falcons and owls did not find statistically significant differences in life-history traits between artificial and natural cavities (e.g. Gehlbach 1994a), other investigations focusing on the same species reported variation in clutch size, hatching success and/or fledging success across distinct nest types, including artificial nest boxes. For instance, larger clutches being laid in nest boxes which are relatively larger than other types of nest sites (cavities in buildings or trees) have been observed in Barn Owls (Tyto alba) in Norfolk, England (Johnson 1994), Tengmalm's Owls (Aegolius funereus) in western Finland (Korpimäki 1984), and Eurasian Kestrels (Falco tinnunculus) in Rome (G. Dell'Omo, personal communication). Hatching success of Barn Owl eggs in Venezuela was higher in boxes compared to natural cavities because the eggs broke less frequently (Lander et al. 1991). Other studies have reported either that fledging success was greater in boxes relative to natural cavities (e.g. van Nieuwenhuyse et al. 2008 studying Little Owls, Athene noctua) or that there was no significant difference in productivity between boxes, buildings and trees (Barn Owls; Johnson 1994). One study on Lesser Kestrels ( $F$. naumanni) found that the fledging success in nest boxes 
did not differ from that recorded in nests located in attic cavities, but was lower than that in nests located in wall cavities (Bux et al. 2008). Sometimes, the effect of boxes may first appear when nestlings try to fledge. For example, in North America, radio-tagged Barn Owl fledgings from marsh locations survived their first flight better than those that fledged from offshore nest boxes or duck blinds (Bendel and Therres 1993). Such studies demonstrate the importance of recording the use of and measuring the characteristics of breeding places other than nest boxes, which can vary greatly depending on location.

Whether nest boxes are safer than other cavities or stick nests may depend on differences in size, height or position between different nest types, the types of protective devices added to nest boxes, and/or nest box relocation across years (Sonerud 1989, 1993; Fargallo et al. 2001; Charter et al. 2007; van Nieuwenhuyse et al. 2008; López et al. 2010; but see Korpimäki 1993). For instance, some species breeding in smaller nest cavities may have fewer surviving fledglings because the cavities are too cramped to allow nestlings to practise motor skills prior to fledging (Klein et al. 2007). Because most Tawny Owl (Strix aluco) fledglings finish their first flight from the nest at a lower height, a relatively lower nest position in combination with absence of perches near the entrance hole might increase the risk for fledglings sitting on the ground, perhaps also making them more vulnerable to mammalian predators, such as red foxes Vulpes vulpes (Sunde 2005). However, Strix and Scops Owl Otus scops fledglings regularly leave the nest before they can fly properly, perhaps to disperse as soon as possible to reduce the risk of small carnivores (e.g. Martes sp.) depredating the whole brood (T. Solonen; R. Arlettaz and A. Sierro, personal communication). In Eurasian Kestrels from Finland, Germany, Spain, and Israel, breeding success was higher in closed-type nests (nest boxes or cavities in buildings or walls) than in open-type nests (pre-existing stick nests), presumably because open nests are more vulnerable to predation, extreme weather conditions, or other environmental factors (Korpimäki 1983; Kostrzewa and Kostrzewa 1997; Fargallo et al. 2001; Charter et al. 2007; see also Carrillo and González-Dávila 2009 for other study sites).

\section{Differences among nest box types}

The way nest boxes are designed, positioned, monitored and maintained may influence a cocktail of abiotic and biotic factors in the nest box chamber at the timing of roosting or breeding. Nest box parameters will probably also interact with external environmental factors expressed differently in different regions (food abundance, weather, nest-site availability, presence of other organisms), and markedly influence the outcome of ecological field investigations. In this context, researchers may inadvertently control or exaggerate the effect of some of these factors on the population or on the studied trait by using specific nest box designs or materials. Nest box design can also affect nest box choice and the development and survival of the eggs or nestlings, or the survival and physical condition of adults exploiting nest boxes (Korpimäki 1985; Bortolotti 1994; Charter et al. 2007; Butler et al. 2009; López et al. 2010; Zingg et al. 2010).

In this context, the internal size of the nest cavity may influence clutch size, depending on the size ranges of the nest chamber, the local population, the species, or the external environments monitored. Tengmalm's Owls from a Finnish study population produced larger clutches in medium-sized and large nest boxes than in small nest boxes during vole peak years, apparently because there are more stored prey in the larger nest box types (Korpimäki 1985). This relationship was not observed in years with severe food constraints. The amount of food stored in artificial nest boxes may therefore influence egg formation directly if females consume these stores before or during the period of egg development, or they can perhaps be used as a cue (Durant et al. 2010) required to anticipate the abundance of food available at the time of rearing nestlings (Hörnfeldt et al. 1990). However, López et al. (2010) studying the same species in the Pyrenees Mountains did not find a significant relationship between clutch size and nest box size, perhaps because of small sample sizes or interactions with key environmental factors that were not taken into account. Valkama and Korpimäki (1999) did not find differences in clutch size or brood size at fledging with respect to nest box size (small, intermediate or large) in Eurasian Kestrels from western Finland, whereas Charter et al. (2007) reported somewhat larger clutches or larger broods with more fledglings in smaller nest boxes than in larger ones. However, Charter et al. (2007) studied Kestrels in nest boxes designed to attract Barn Owls. Clutch size, brood size at fledging and nest success were all unaffected by box size in American Kestrels ( $F$. sparverius) from Saskatchewan, Canada (Bortolotti 1994), although the American Kestrels apparently preferred the larger nest boxes provided in choice experiments. Clearly, clutch sizenest box size relationships, and the underlying mechanisms causing these relationships, vary between local study populations within species or across species settled in the same or different geographic regions (see Charter et al. 2007).

Several other nest box variables seem to affect the occupation and breeding success of a nest box. The size of the entrance hole obviously determines which individuals or species will occupy nest boxes and hence how their lifehistory traits will be expressed in the presence of other organisms (Bavoux et al. 1991; Valdez et al. 2000; López 
et al. 2010). While larger-bodied species require large entrances, smaller individuals or species may prefer to breed in nest boxes with small entrance holes to reduce risks related to predation or competition. The dimensions of the nest box characteristics apparently influence interactions between Eurasian Kestrels and Barn Owls in Israel (Charter et al. 2007, 2010b), between Tawny Owls and Tengmalm's Owls in southern Finland and Spain (Solonen 1993; López et al. 2010), between Tengmalm's Owls, Ural Owls (S. uralensis) and Eagle Owls (Bubo bubo) in western Finland (Hakkarainen and Korpimäki 1996), between Barn Owls and Tawny Owls in northeast England (Petty et al. 1994), and between Eurasian Kestrels and Tawny Owls in Rome (D. Costantini and G. Dell'Omo, personal communication). In western Finland, Tengmalm's Owls mostly avoided breeding in the largest boxes (internal diameter 26-35 cm, entrance hole $15-18 \mathrm{~cm}$ ) probably because Ural Owls could have entered them and physically removed the Tengmalm's Owls (Hakkarainen and Korpimäki 1996).

A more subtle impact of entrance hole size on heterospecific intrusion was found for Tawny Owls in Denmark. Here, the prevalance of blood parasites (Leucozytozoon, Trypanosoma) was much higher for Tawny Owl nestlings in boxes with a wide entrance hole $(30 \mathrm{~cm} \times 40 \mathrm{~cm}$ as designed for Eurasian Kestrels) compared to those from natural cavities or nest boxes with a narrow entrance (15 cm diameter) (P. Sunde, unpublished data). While as yet untested, it is possible that insect vectors, and perhaps ectoparasites, may have easier access or can more easily detect larger entrances, or perhaps parents block the entrance hole when insect vectors are noticed. In addition, large entrance holes in small and shallow nest box chambers could increase the probability of premature fledging, for instance when nestlings are disturbed by the intrusions of heterospecifics or by humans which possibly increase stress levels (Roulin et al. 2010).

Local weather may influence the preferences for certain nest cavities with birds avoiding those with entrance holes oriented in the direction of prevailing rain or wind (Exo 1981; Sullivan et al. 2003). Orientation of the entrance influences site selection of natural cavities and artificial cavities in American Kestrels, possibly because internal nest temperatures differ as a function of orientation (Balgooyen 1990; Butler et al. 2009). In a rural ecosystem in Israel, the number of fledged young per breeding attempt and the hatching success of Eurasian Kestrels nesting in large nest boxes decreased with increasing rain (Charter et al. 2007). On the other hand, overheating of boxes during heat waves may cause hyperthermia or mortality of entire broods of Barn Owls and Kestrels (Meyrom et al. 2009). In hot environments, Barn Owls apparently prefer to settle in cooler than in warmer nest boxes where they also produce more fledglings per breeding attempt (Charter et al. 2010c).
Prey stored in nest boxes decompose more rapidly late in the season, i.e. when nest box environments become warmer, perhaps reducing availability of optimal prey for broods produced late in the season (A. Roulin, personal communication). It is also possible that decaying prey items such as rodents which are vectors or hosts of microorganisms causing disease (Combes 2001), or sources of ectoparasites, may be more or less likely to transmit the infection to the nest box occupants, depending on the micro-climate (e.g. Fargallo et al. 2001 for ectoparasites), or the types of prey (e.g. sick vs. healthy; Temple 1986; Valkama et al. 2005) influencing pathogen reproduction. Because falcons and owls do not add their own nest material to cavities, the presence of old nest material in a box or the experimental addition of sawdust or wood chips may improve insulation and hence the attractiveness of the site, especially in environments with more extreme weather conditions (López et al. 2010). In addition, old nest material not removed from nest chambers may increase the probability that ectoparasites develop in the nest box chamber, possibly influencing avian breeding success (Møller 1994; Roulin et al. 2007).

\section{The reporting of nest box design in recent publications}

\section{Methods}

To examine whether recent literature sources (national and international scientific journals, book chapters, proceedings of scientific meetings) reported details on nest box design and position, we examined the "Methods" sections of publications involving the most commonly investigated cavity-nesting falcons and owls in Europe and North America (Table 1) following similar approaches as those presented in Lambrechts et al. (2010). We divided the literature sources into two categories: those published before the publications of the Gehlbach symposium ("older" papers published before 1995), and those published from 1995 onwards ("more recent" publications). Based on the recommendations of Møller (1989, 1992, 1994), we predicted that descriptions of nest box characteristics would be more frequent among articles published after 1994. Publications were classified according to research category of the journal of publication (ornithology vs. ecology vs. others, including zoological, behavioural and physiologyoriented papers) and the 5-year impact factor from 2009 following the criteria presented on the Web of Knowledge. For journals that have changed their name (Journal für Ornithologie replaced by Journal of Ornithology, Ornis Scandinavica replaced by Journal of Avian Biology, Holarctic Ecology replaced by Ecography), the latest impact factors available were used. We predicted that nest box 
Table 1 Percentage of publications describing or citing zero or more nest box characteristics in analysed papers during two periods: $<1995$ and 1995 or later

\begin{tabular}{|c|c|c|c|c|c|c|}
\hline \multirow[t]{2}{*}{ Taxonomic name } & \multirow[t]{2}{*}{ Period } & \multirow[t]{2}{*}{$\begin{array}{l}\text { Source } \\
\text { numbers }\end{array}$} & \multicolumn{4}{|c|}{$\begin{array}{l}\text { Nest box characteristics } \\
\text { described or cited }(\%)\end{array}$} \\
\hline & & & 0 & 1 & 2 & $>2$ \\
\hline \multicolumn{7}{|l|}{ Falconiformes } \\
\hline \multirow[t]{2}{*}{ Falco naumanni } & $<1995$ & - & - & - & - & - \\
\hline & $\geq 1995$ & 3 & 33.3 & 0 & 0 & 66.7 \\
\hline \multirow[t]{2}{*}{ Falco sparverius } & $<1995$ & 21 & 66.7 & 4.8 & 0 & 28.6 \\
\hline & $\geq 1995$ & 42 & 38.1 & 2.4 & 4.8 & 54.8 \\
\hline \multirow[t]{2}{*}{ Falco tinnunculus } & $<1995$ & 13 & 61.5 & 0 & 0 & 38.5 \\
\hline & $\geq 1995$ & 61 & 73.8 & 16.4 & 0 & 9.8 \\
\hline \multicolumn{7}{|l|}{ Strigiformes } \\
\hline \multirow[t]{2}{*}{ Aegolius funereus } & $<1995$ & 34 & 35.3 & 8.8 & 2.9 & 52.9 \\
\hline & $\geq 1995$ & 26 & 57.7 & 0 & 3.8 & 38.5 \\
\hline \multirow[t]{2}{*}{ Athene noctua } & $<1995$ & 18 & 72.2 & 11.1 & 0 & 16.7 \\
\hline & $\geq 1995$ & 11 & 90.9 & 0 & 0 & 9.1 \\
\hline \multirow[t]{2}{*}{ Otus asio } & $<1995$ & 12 & 83.3 & 0 & 0 & 16.7 \\
\hline & $\geq 1995$ & 5 & 40.0 & 0 & 0 & 60.0 \\
\hline \multirow[t]{2}{*}{ Otus scops } & $<1995$ & 0 & 0 & 0 & 0 & 0 \\
\hline & $\geq 1995$ & 4 & 50.0 & 0 & 0 & 50.0 \\
\hline \multirow[t]{2}{*}{ Strix aluco } & $<1995$ & 4 & 50.0 & 0 & 0 & 50.0 \\
\hline & $\geq 1995$ & 29 & 79.3 & 0 & 0 & 20.7 \\
\hline \multirow[t]{2}{*}{ Strix uralensis } & $<1995$ & 4 & 100.0 & 0 & 0 & 0 \\
\hline & $\geq 1995$ & 10 & 100.0 & 0 & 0 & 0 \\
\hline \multirow[t]{2}{*}{ Tyto alba } & $<1995$ & 10 & 40.0 & 0 & 10.0 & 50.0 \\
\hline & $\geq 1995$ & 28 & 64.3 & 0 & 0 & 35.7 \\
\hline \multirow[t]{2}{*}{ Total } & $<1995$ & 116 & 57.8 & 5.2 & 1.7 & 35.3 \\
\hline & $\geq 1995$ & 221 & 65.2 & 5.0 & 1.4 & 28.5 \\
\hline
\end{tabular}

The percentages of publications with information on none $(0)$, one (1), two (2) or more than two $(>2)$ nest box characteristics are indicated

descriptions would be more detailed in publications dealing with ornithology or ecology, assuming nest box design would be considered as an important environmental key factor for the development or expression of individual lifehistory traits or population dynamics (see above). We predicted more detailed descriptions of nest boxes in publications with lower 5-year impact factors, presuming these journals could provide more space per article. We also recorded other information about the publication, including the name of the first author, the number of authors, the number of institutional addresses, the country in which the research was performed, and the focal species. Lastly, we categorised the research topic of the paper as focusing on reproductive attributes (i.e. data focused on events within the nest box: eggs, incubation, brood size, chick phenotypes, nestling growth or behaviour, breeding success, parental care behaviour with nestlings) or not (i.e. data focused on information obtained outside the nest boxes: adult vocal behaviour, population dynamics, dispersal behaviour, working effort, winter roosting behaviour, foraging behaviour, diet composition, survival after fledging, pair formation, presentation of trapping device).

We located relevant publications by using the scientific or common names of species as key words in leading electronic databases (ISI Web of Science, Biblio-Vie, BiblioSHS, CEFE-CNRS library; September-November 2010). We also searched the extensive collection of reprints possessed by collaborators working on these species. We searched the reference section of each of these publications to identify other relevant publications mentioned in the "Methods" sections. Only publications indicating nest boxes have been used as tools were included in the literature survey, which makes this survey conservative, due to the possibility that many publications may not have reported nest box use. We are aware that publications from the same team are often not independent units, but we have chosen to not include team as a factor because this reflects the probability that a student gathers information in the first paper she or he reads, regardless of the author's previous publication record, and because it allows comparison with the nest box study review on passerines presented in Lambrechts et al. (2010).

To model the probability whether or not a paper addressed nest box information, we performed a series of general linear mixed models with a logit link function and a binary error distribution (PROC GLIMMIX; conducted by P. Sunde). Because many of the random effects (journal name, first author name, country, and focal species) were inter-correlated and inclusion of all random effects did not allow all models to converge, all random effects were analysed to select the most informative one. First author accounted for a plurality of the variation $(Z=3.14$, $P=0.002$; all others $P>0.09$ ), so this random effect was included in all subsequent analyses on fixed effects. We then ran a series of fixed effect analyses with each fixed effect (time period, journal category, journal impact factor, and research topic) as the sole fixed effect, and one model with all fixed effects included simultaneously. Then, because it is possible that several of these categories may interact with each other (e.g. only ornithological journals may have increased reporting of nest box characteristics after the 1994 symposium), we ran another series of analyses with all second order interactions of the aforementioned fixed effects. All statistics were performed using SAS 9.2 (Cary, NC, USA).

Lack of reporting of nest box characteristics

Thirty-seven percent (95\% confidence interval: $30-45 \%$ ) of the sources verified addressed nest box information (a total 
of 337 literature sources; Table 1). No fixed effect, either alone or when included in the statistical model with all fixed effects, significantly predicted the probability that a paper included any nest box parameter descriptions (6 variables tested: all $F<2.42$, all $P>0.12$ ). Within models that included the interactions of two fixed effects (additional 6 models tested), one interaction (period $\times$ research topic) significantly predicted whether a paper included any nest box parameter descriptions $\left(F_{3,327}=3.06\right.$, $P=0.028)$, while all others were not significant at the $\alpha=0.05$ level (all $F<2.56$, all $P>0.079$ ). The final model that utilised the significant interaction showed no significant effect of period $\left(F_{1,292}=0.06, P=0.81\right)$, but significant effects of both research topics $\left(F_{1,327}=4.20\right.$, $P=0.041)$ and the interaction between period and research topic $\left(F_{1,327}=5.14, P=0.024\right.$; Fig. 1$)$. Given that 12 reasonably independent models were tested, at least one $P$ value $\leq 0.028$ would appear by chance alone with $29 \%$ probability $\left[1-(1-0.028)^{12}\right]$. Rigorously, the single significant result can therefore be considered a random event. This conclusion would not change if the obtained $P$ values were adjusted for multiple tests (Chandler 1995).

The statistical analysis of the published literature, together with the information presented in Table 1, strongly indicate that nest box design has often remained underreported in the literature. This conclusion is also based on the following observations.

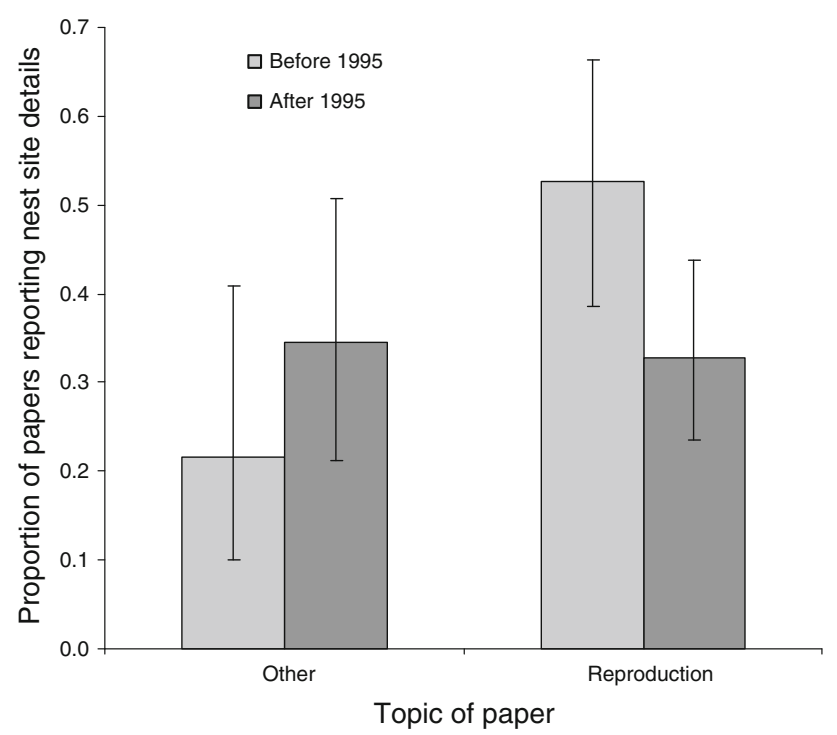

Fig. 1 Proportion of literature sources (error bars are 95\% confidence intervals) that report nest box descriptions as a function of time period published and the paper's research topic. There was a significant interaction between period and research topic. Post hoc tests revealed significant differences between periods for papers about reproduction $(P=0.026)$ and between topics for papers published before $1995(P=0.006)$
Detailed descriptions of nest box design are rarely available in publications

Box descriptions provided were often incomplete or imprecise, reporting dimensions without specifying whether these referred to the size of the whole box (exterior) or just the nest box chamber (interior). Thus, the thickness of the nest box wall was often not reported (see Korpimäki 1985; Eschenbauch et al. 2009 for exceptions), despite some researchers working with owls recognising that wall thickness may influence the thermal environment of the nest box chamber and hence winter survival, egg-hatching success or nestling survival in extreme environmental conditions (Korpimäki 1984, 1985; Johnson 1994).

Other aspects of box construction, such as the material used (e.g. metal, plastic, or wooden) were even less frequently reported than size (but see, e.g., Ravussin et al. 2001; van Nieuwenhuyse et al. 2008). Only some authors reported whether there were drainage holes in the bottom as used by the team of G. Dell'Omo to study Eurasian Kestrels. Such factors could have a significant impact on the conditions in which eggs are incubated or nestlings reared, and perhaps influence the duration that nestlings stay in the nest (Knötzsch 1978; Wendt 1978; Illner 1979). Also, no scientific justification was provided for the wood types used to construct the nest boxes, even though it is possible that wood chemistry affects the decomposition rate of prey stored in nest boxes or influences the invertebrate communities there (Philips and Dindal 1977). The volatile or other chemical compounds emitted by the wood used to construct nest boxes, perhaps in interaction with the micro-climate inside the nest box chamber, may influence functioning or development of eggs, nestlings, or adults, although very few studies have looked at this in birds of prey (see Ontiveros et al. 2008; Lambrechts et al. 2010 for details).

In addition to the box characteristics themselves, the type and amount of substrates added to the box by researchers, such as wood shavings, sawdust or vegetation, were rarely described, as illustrated in studies of American Kestrels (Hamerstrom and Hamerstrom 1973; Bortolotti 1994; Rohrbaugh and Yahner 1997; Beasley and Parrish 2009; Eschenbauch et al. 2009; Santolo and Yamamoto 2009; Steenhof and Peterson 2009), although the types and maintenance procedures of these substrates may significantly influence nest sanitation or comfort for nestlings or adults (Møller 1994; Roulin et al. 2007; López et al. 2010). For instance, Wimberger (1984) suggested that greenery added to line nests of open-nesting raptors of genera Accipiter, Buteo and Pernis may also improve nest sanitation. Perhaps wood chips emitting aromatics (Eucalyptus or pine; e.g. see Ontiveros et al. 2008) added in wooden nest boxes possess chemical properties impacting the 
health and physiology of individuals at the time of reproduction.

The impact of nest box design on aspects of intraspecific or interspecific communication has also been ignored in the published literature, although plumage colours and vocal begging signals are known to be important in Barn Owls (Roulin et al. 2000, 2003), and the potential importance of light intensity inside nest boxes has been recognised for years (Bortolotti 1994). In particular, the size of the entrance hole, the depth of the cavity, the orientation of the box, or its placement relative to other habitat structures may affect internal light levels, but this has to the best of our knowledge rarely been measured in cavities exploited by diurnal species (see Butler et al. 2009 for an exception in American Kestrels). A comparative study on parental behaviour in passerines using nest boxes and Northern Flickers (Colaptes auratus) using deep tree cavities found that the parent's ability to detect and feed nestlings depended on ambient light levels, cavity depth, and on nestling coloration (Wiebe and Slagsvold 2009). Therefore, it is probable that light levels also influence a cavitynesting raptor's ability to detect nestlings, or to remove ectoparasites from the nestlings or nest chamber. The possibility that features of the box influence the sounds involved in vocal communication, such as nestling begging calls, also deserves future study.

\section{Nest boxes often represent a biased fraction of the properties of natural nest-types}

Although the nest boxes provided in many local study sites were probably made with a consistent design in order to minimise potential confounding variables and maximise sample sizes (e.g. through a significant reduction of nest predation; Julliard et al. 1997), the scientific arguments for using a particular nest type or for placing them in a particular way (orientation, height above the ground and substrate) is often not provided or not taken into account. Several local long-term studies tried out a limited number of nest box designs to ultimately propose an optimal design that should maximise reproductive output for a given local population or species (Korpimäki 1985, 1987a, b; De Bruijn 1994; van Nieuwenhuyse et al. 2008; G. Dell'Omo, unpublished data). These studies did not always explain in detail why the initial nest box types used had been selected among the many other conceivable alternative nest types, or never published the methods and results of initial studies that provided the arguments for the use of one particular nest box design in a local long-term study. In preliminary investigations, Gehlbach (1994b) selected a small number of nest boxes reflecting as close as possible the range of characteristics of natural cavities exploited in the same region by the model species investigated. In some cases, unconventional boxes such as those with multiple chambers may be suitable for species like Tawny Owls (P. Sunde, personal communication). Practical reasons impose the use of a small number of nest box type classes, in which only one or two nest box properties are altered (e.g. small vs. intermediate vs. large interior bottom size and entrance hole, controlling for other nest box characteristics). The few studies on nest box orientation that investigated a nest box property as a "continuous" variable currently provide the best examples for more profound investigations on aspects of nest box position where confounding (changeable) factors could be controlled in a more efficient manner (Butler et al. 2009; Charter et al. 2010c).

Nest box designs and research protocols vary across study sites at macro-geographic scales

While a certain research team or monitoring organisation often uses a standard box type across their different study sites, different research groups may use either similar or different box designs without providing a scientific justification. For instance, Hayward et al. (1992) working with Tengmalm's Owls in the U.S.A. used the type of nest box considered to be optimal for reproduction in Tengmalm's Owls from western Finland (Korpimäki 1985). Our review indicated that typically different research groups studying the same species in different locations did not use the same nest box design or protocols (Baucells et al. 2003; van Nieuwenhuyse et al. 2008). For instance, the nest box design proposed to investigate Tengmalm's Owls in Switzerland (Ravussin et al. 2001) and Germany (März 1968) differs significantly from designs used in Finland (Korpimäki 1985) or Spain (López et al. 2010), without providing scientific arguments why the nest box shapes should differ across European regions or countries. According to Ravussin et al. (2001), nest boxes constructed from PVC tubes are more efficient in attracting breeding Tengmalm's Owls than other nest box types, probably because the PVC boxes are more efficient in excluding European pine martens (Martes martes) in that study population. Thus, in the course of long-term studies, nest box design or position may be adjusted to local environmental conditions (predation pressures), without necessarily always indicating this in the published literature, perhaps explaining a significant part of the spatiotemporal variation in nest box design currently observed (see case studies in Little Owls; van Nieuwenhuyse et al. 2008).

In some regions, such as southern and central Finland and the eastern Pyrenees, there are a large number of artificial nest boxes erected by well-meaning citizens, including birdwatchers and hunters, and there are no or only a few general standards that are applied for the construction of these nest boxes. Thus, one reason for the lack 
of detailed descriptions of artificial nest boxes from certain regions might be their enormous heterogeneity and the difficulty to classify them properly (T. Solonen, personal communication; López et al. 2010), although natural cavities expressing similar or more heterogeneity in structure have been described in some publications on owls (Korpimäki 1984; Gehlbach 1994b; Tomé et al. 2004).

Using different nest box designs probably influences the procedures and the time needed to monitor the occupants of nest boxes. Differences in the ease and frequency of monitoring nest sites could explain some large-scale variation in the accuracy or precision of reported breeding parameters from different geographic sites, for example in American Kestrels (Smallwood et al. 2009). Beasley and Parrish (2009), studying the same species, used a spotting scope to monitor nests in tubes of transmission towers at $30 \mathrm{~m}$ above the ground, and a ladder to inspect PVC boxes placed at $4.5 \mathrm{~m}$ above the ground, which perhaps caused different levels of stress and disturbance to adults or nestlings. To the best of our knowledge, no one verified scientifically whether diurnal or nocturnal inspections may influence sleeping patterns and breeding or parental activities in the following day(s) or night(s).

Because the detailed procedures of nest box monitoring and maintenance are rarely published, they may not be efficiently transmitted among different research teams even when an effort is made to collaborate. For instance, the team of G. Dell' Omo for many years added dry Sphagnum turf at the bottom of nest boxes aimed to attract breeding Eurasian Kestrels around Rome. The nest box design was given to another North Italian research team without providing instructions to add turf or other bedding material inside the nest boxes. In this new North Italian study population, established in 1999, Eurasian Kestrels started to occupy the nest boxes only 3-4 years after they were installed, possibly because the 4-year-old nest boxes contained old sparrow nests which significantly increased the desirability of these nest boxes for breeding Eurasian Kestrels. Thus, at macro-geographic scales, replicates in nest box design and monitoring protocols across study sites are often inconsistent, which precludes a good experimental design (see Hurlbert 1984) when the goal is to compare large geographical areas.

\section{Variation in nest box characteristics is often ignored in statistical analyses}

If a single type of nest box is impossible or undesirable to standardise across study sites, one can enter nest box type as a factor in statistical analyses of variation at the individual or population level (Carrillo and González-Dávila 2009), but this has rarely been done, either because the information was unavailable at the time the analyses were done (see Klein et al. 2007), or because the significance of nest box design has been considered to be negligible (Gehlbach 1994a; Charter et al. 2007). Lack of standardisation or unreported changes in nest box design within local study plots in the course of long-term studies could thus (1) bias inferences on population trends within areas, (2) prevent analyses of temporal trends in population responses to biotic and abiotic factors, and/or (3) compromise meta-analyses and thus the generality of findings. Including nest box design as an environmental key factor in meta-analyses could help to point out outlier populations or gain a better understanding of the statistical noise facing these analyses (see Zuur et al. 2010 for procedures in data exploration).

\section{Concluding remarks}

The present literature review on secondary hole-nesting raptors (outlined above) and a recent review on passerines (Lambrechts et al. 2010) provide similar observations and conclusions. Publications or unpublished observations from older and more recent studies (<1995 vs. $\geq 1995)$ report that aspects of nest box design (e.g. size of the whole box, internal size of the nest cavity, size of entrance hole, nest box material, presence or absence of drainage holes, wall thickness), location (e.g. nest box height, orientation of entrance hole, substrate to which the box is attached) and/ or maintenance procedures (e.g. addition of substrate on the nest box floor) can influence both the probability that a box is occupied and the expression of avian life-history traits of nest box occupants (clutch size, egg hatching success, breeding success, chick phenotype). However, many recent publications do not provide any details on nest box design, despite several published calls to increase reporting of such information. Because the vast majority of avian nest box studies focus on Falconiformes, Strigiformes and Passeriformes, we believe that our general conclusions will not change if other avian nest box exploiters are added to these reviews.

While we encourage interpreting these results with caution, we found that generalist journals with high impact factors were less likely to contain methodological details in more recent publications, presumably because journal editors and reviewers do not always know the burgeoning literature well enough to advise which information should be excluded from short papers, and researchers themselves often underappreciated the significance of box design (e.g. Gehlbach 1994a). Clearly, it is important for rigorous scientific research that the methods are adequately described and fully replicable (Hurlbert 1984; Hairston 1989). Therefore, we urge journals, even those with strict page limits, to encourage the detailed reporting of box design whether in appendices, online supplements, or by citing 
former publications which do contain this information. Our recommendations addressed to authors, referees and editors are the same as those for passerine studies, and they include detailed reporting of location and design of boxes, and the detailed description of procedures related to maintenance, protection and inspection of boxes (Lambrechts et al. 2010, p. 10).

In addition to merely reporting box characteristics and protocol details, we encourage more research on how box characteristics and maintenance or monitoring procedures actually influence individual life-history expressions and population dynamics. Most, if not all, of the research projects and experiments proposed for passerines are also applicable to other cavity-nesting birds, although there are certainly logistic constraints which may prevent exact replication of box types and placements in free-ranging populations (see Lambrechts et al. 2010). Also, numerous characteristics of boxes may be acting simultaneously and it may be difficult to tease these apart in free-ranging populations (Bortolotti 1994). However, Korpimäki (1985) and López et al. (2010) showed that the consequences of different combinations of nest box characteristics could indeed be investigated in owls. In general, logistic constraints for experiments with falcons and owls may be more challenging than for passerines because the former group of birds have larger body sizes, larger territories, and higher nest-site positions, and so it is more difficult to obtain sufficient sample sizes. Also, in many cases, and especially in the exploited forest of Europe, there are few suitable natural nesting cavities so it is often difficult to judge what is a "natural" or "optimal" nesting site.

It is probably naïve to think that a single box design or placement for a given species is "optimal" for all situations and all habitats (Charter et al. 2007). In the wild, spatiotemporal fluctuations in weather conditions or predation pressures may favour the maintenance and use of a variety of cavity types (van Nieuwenhuyse et al. 2008). However, it would be informative to study the interaction effects of box characteristics with environmental factors using longterm or large-scale studies. As an aid to this endeavour are nest boxes numbering into the thousands monitored by amateur ornithologists (Saurola 2008) or other citizen science projects. We therefore finally suggest that nest box design is an environmental key factor for individual survival, reproduction, and population dynamics, which could also be investigated in the framework of such large-scale monitoring networks.

Acknowledgments M. Lambrechts wishes to thank A. Gorgeon and collaborators for constructive help with literature research and the maintenance of the library at CEFE. R. Arlettaz wishes to thank E. Revaz and A. Sieroo who provided information from Suisse study populations. D. Costantini wishes to thank S. Casagrande and F. Mezzavilla who provided information from Italian study populations.

\section{References}

Arlettaz R, Fournier J, Juillard M, Lugon A, Rossel D, Sierro A (1991) Origines du déclin de la population relictuelle du Hibou petit-duc, Otus scops, dans les Alpes valaisannes (sud-ouest de la Suisse): une approche empirique. In: Juillard RM et al (eds) Rapaces nocturnes. Acte du 30e Colloque interrégional d'ornithologie Porrentruy (Suisse): 2-3-4 novembre 1990. Nos Oiseaux

Arlettaz R, Schaub M, Fournier J, Reichlin TS, Sierro A, Watson J, Braunisch V (2010) From publications to public actions: when conservation biologists bridge the gap between research and implementation. Bioscience 60:835-842

Balgooyen TG (1990) Orientation of American kestrel nest cavities: revisited. J Raptor Res 24:27-28

Baucells J, Camprodon J, Cerdeira J, Vila P (2003) Guía de las Cajas nido y Comederos para aves y otros vertebrados. Lynx, Barcelona

Bavoux C, Burneleau G, Nicolau-Guillaumet P (1991) Aspects de la biologie de reproduction du Hibou petit-duc. Alauda 59:65-71

Beasley HA, Parrish JW Jr (2009) Breeding population of Southeastern American kestrels in tubular cross-armed transmission towers in South-Central Georgia. J Raptor Res 43:372-376

Bendel PR, Therres GD (1993) Differential mortality of barn owls during fledging from marsh and off-shore nest sites. J Field Ornithol 64:326-330

Bortolotti GR (1994) Effects of nest box size on nest-site preference and reproduction in American kestrels. J Raptor Res 28:127-133

Bortolotti GR, Dawson RD, Murza GL (2002) Stress during feather development predicts fitness potential. J Anim Ecol 71:333-342

Brommer JE, Karell P, Pihlaja T, Painter JN, Primmer CR, Pietiäinen H (2003) Ural owl sex allocation and parental investment under poor food conditions. Oecologia 137:140-147

Butler MW, Whitman BA, Dufty AM Jr (2009) Nest box temperature and hatching success of American kestrels varies with nest box orientation. Wilson J Ornithol 121:778-782

Bux M, Giglio G, Gustin M (2008) Nest box provision for lesser kestrel Falco naumanni populations in the Apulia region of southern Italy. Conserv Evidence 5:58-61

Carrillo J, González-Dávila E (2009) Latitudinal variation in breeding parameters of the common kestrel Falco tinnunculus. Ardeola $56: 215-228$

Chandler CR (1995) Practical considerations in the use of simultaneous inference for multiple tests. Anim Behav 49:524-527

Charter M, Izhaki I, Bouskila A, Leshem Y (2007) The effect of different nest types on the breeding success of Eurasian kestrels (Falco tinnunculus) in a rural ecosystem. J Raptor Res 41:143-149

Charter M, Izhaki I, Leshem Y (2010a) Does nest basket size affect breeding performance of long-eared owls and Eurasian kestrels? J Raptor Res 44:314-317

Charter M, Izhaki I, Leshem Y (2010b) Effects of risk of competition and predation on large secondary cavity breeders. J Ornithol 151:791-795

Charter M, Meyrom K, Leshem Y, Aviel S, Izhaki I, Motro Y (2010c) Does nest box location and orientation affect occupation rate and breeding success of barn owls in a semi-arid environment? Acta Ornithol 45:115-119

Clutton-Brock TH (ed) (1988) Reproductive success. University of Chicago Press, Chicago

Combes C (2001) Parasitism: the ecology and evolution of intimate interactions. University of Chicago Press, Chicago

Costantini D, Casagrande S, Carello L, Dell'Omo G (2009) Body condition variation in kestrel (Falco tinnunculus) nestlings in relation to breeding conditions. Ecol Res 24:1213-1221

De Bruijn O (1994) Population ecology and conservation of the barn owl Tyto alba in farmland habitats in Liemers and Achterhoek (The Netherlands). Ardea 82:1-109 
Dijkstra C, Daan S, Buker JB (1990) Adaptive seasonal variation in the sex ratio of kestrel broods. Funct Ecol 4:143-147

Doody JS (1994) Winter roost-site use by female American kestrels (Falco sparverius) in Louisiana. J Raptor Res 28:9-12

Duckett JE (1991) Management of the barn owl (Tyto alba javanica) as a predator of rats in oil palm (Elaeis quineensis) plantations in Malaysia. Birds Prey Bull 4:11-24

Durant JM, Gendner J-P, Handrich Y (2010) Behavioural and body mass changes before egg laying in the barn owl: cues for clutch size determination? J Ornithol 151:11-17

Eschenbauch JE, Jacobs EA, Rosenfield RN (2009) Nest box occupancy and reproductive performance of kestrels in Central Wisconsin. J Raptor Res 43:365-369

Exo K-M (1981) Zur Nistökologie des Steinkauzes (Athene noctua). Vogelwelt 102:161-180

Exo K-M (1992) Population ecology of little owls Athene noctua in Central Europe: a review. In: Galbraith CA, Taylor IR, Percival $\mathrm{S}$ (eds) The ecology and conservation of European owls. Peterborough, Joint Nature Conservation Committee (UK Nature Conservation, No. 5), pp 64-75

Fargallo JA, Blanco G, Potti J, Viñuela J (2001) Nestbox provisioning in a rural population of Eurasian kestrels: breeding performance, nest predation and parasitism. Bird Study 48:236-244

Franco AMA, Marques JT, Sutherland WJ (2005) Is nest-site availability limiting lesser kestrel populations? A multiple scale approach. Ibis 147:657-666

Gard NW, Bird DM (1990) Breeding behaviour of American kestrels raising manipulated brood sizes in years of varying prey abundance. Wilson Bull 102:605-614

Gehlbach FR (1994a) A symposium on using nest boxes to study raptors: do the boxes provide virtual reality? J Raptor Res 28:125-126

Gehlbach FR (1994b) Nest box versus natural-cavity nests of the eastern screech-owl: an exploratory study. J Raptor Res 28:154-157

Hairston NG (1989) Ecological experiments. Purpose, design, and execution. Cambridge University Press, Cambridge

Hakkarainen H, Korpimäki E (1996) Competitive and predatory interactions among raptors: an observational and experimental study. Ecology 77:1134-1142

Hamerstrom F, Hamerstrom FN (1973) Nest boxes: an effective management tool for kestrels. J Wildl Manag 37:400-403

Hayward GD, Steinhorst RK, Hayward PH (1992) Monitoring boreal owl populations with nest boxes: sample size and cost. J Wildl Manag 56:777-785

Hörnfeldt B, Carlsson B-G, Löfgren O, Eklund U (1990) Effects of cyclic food supply on breeding performance in Tengmalm's owl (Aegolius funereus). Can J Zool 68:522-530

Hurlbert SH (1984) Pseudoreplication and the design of ecological field experiments. Ecol Monogr 54:187-211

Illner H (1979) Erfahrungsbericht über Steinkauzbruten in Niströhren. Deutscher Bund für Vogelschutz, AG zum Schutz bedrohter Eulen. Informationsblatt 9:6

Johnson PN (1994) Selection and use of nest sites by barn owls in Norfolk, England. J Raptor Res 28:149-153

Julliard R, McCleery RH, Clobert J, Perrins CM (1997) Phenotypic adjustment of clutch size due to nest predation in the great tit. Ecology 78:394-404

Kelly CD (2006) Replicating empirical research in behavioral ecology: how and why it should be done but rarely ever is. Q Rev Biol 81:221-236

Kirk DA, Hyslop C (1998) Population status and recent trends in Canadian raptors: a review. Biol Cons 83:91-118

Klein A, Nagy T, Csörgő T, Mátics R (2007) Exterior nest boxes may negatively affect barn owl Tyto alba survival: an ecological trap. Bird Conserv Int 17:263-271
Knötzsch G (1978) Ansiedlungsversuche und Notizen zur Biologie des Steinkauzes (Athene noctua). Vogelwelt 99:41-54

Koenig WD, Gowaty PA, Dickinson JL (1992) Boxes, barns, and bridges: confounding factors or exceptional opportunities in ecological studies? Oikos 63:305-308

Korpimäki E (1983) Tuulihaukkapönttökokeilun tuloksia. Lintumies 18:132-137

Korpimäki E (1984) Clutch size and breeding success of Tengmalm's owl Aegolius funereus in natural cavities and nest boxes. Ornis Fennica 61:80-83

Korpimäki E (1985) Clutch size and breeding success in relation to nest box size in Tengmalm's Owl Aegolius funereus. Holarctic Ecol 8:175-180

Korpimäki E (1987a) Clutch size, breeding success and brood size experiments in Tengmalm's owl Aegolius funereus: a test of hypotheses. Ornis Scand 18:277-284

Korpimäki E (1987b) Selection for nest-hole shift and tactics of breeding dispersal in Tengmalm's owl Aegolius funereus. J Anim Ecol 56:185-196

Korpimäki E (1988a) Effects of territory quality on occupancy, breeding performance and breeding dispersal in Tengmalm's owl. J Anim Ecol 57:97-108

Korpimäki E (1988b) Costs of reproduction and success of manipulated broods under varying food conditions in Tengmalm's owl. J Anim Ecol 57:1027-1039

Korpimäki E (1993) Does nest-hole quality, poor breeding success or food depletion drive the breeding dispersal of Tengmalm's owls. J Anim Ecol 62:606-613

Kostrzewa R, Kostrzewa A (1997) Der Bruterfolg des Turmfalken Falco tinnunculus in Deutchland: Ergebnisse 1985-1994. J Ornithol 138:73-82

Laaksonen T, Fargallo JA, Korpimäki E, Lyytinen S, Valkama J, Pöyri V (2004) Year- and sex-dependent effects of experimental brood sex ratio manipulation on fledging condition of Eurasian kestrel. J Anim Ecol 73:342-352

Lambrechts MM, Adriaensen F, Ardia DR, Artemyev AV, Atiénzar F, Bańbura J, Barba E, Bouvier J-C, Camprodon J, Cooper CB, Dawson RD, Eens M, Eeva T, Faivre B, Garamszegi LZ, Goodenough AE, Gosler AG, Grégoire A, Griffith SC, Gustafsson L, Scott Johnson L, Kania W, Keišs O, Llambias PE, Mainwaring MC, Mänd R, Massa B, Mazgajski TD, Møller AP, Moreno J, Naef-Daenzer B, Nilsson J-A, Norte AC, Orell M, Otter KA, Park CR, Perrins CM, Pinowski J, Porkert J, Potti J, Remeš V, Richner H, Rytkönen S, Shiao M-T, Silverin B, Slagsvold T, Smith HG, Sorace A, Stenning MJ, Stewart I, Thompson CF, Török J, Tryjanowski P, van Noordwijk AJ, Winkler DW, Ziane N (2010) The design of artificial nestboxes for the study of secondary hole-nesting birds: a review of methodological inconsistencies and potential biases. Acta Ornithol 45:1-26

Lander E, Lopez J, Diaz C, Colmenares M (1991) Population biology of the barn owl (Tyto alba) in Guarico State, Venezuela. Birds Prey Bull 4:167-171

Lõhmus A (2003) Do Ural owls (Strix uralensis) suffer from the lack of nest sites in managed forests? Biol Cons 110:1-9

López BC, Potrony D, López A, Badosa E, Bonada A, Saló R (2010) Nest box use by boreal owls (Aegolius funereus) in the Pyrenees mountains in Spain. J Raptor Res 44:40-49

März R (1968) Der Rauhfusskauz. Die Neue Brehm-Bücherei, Wittenberg-Lutherstadt

Meyrom K, Motro Y, Leshem Y, Aviel S, Izhaki I, Argyle F, Charter M (2009) Nest box use by the barn owl Tyto alba in a biological pest control program in the Bei She'an valley, Israel. Ardea 97:463-467

Møller AP (1989) Parasites, predators and nest boxes: facts and artefacts in nest box studies of birds? Oikos 56:421-423 
Møller AP (1992) Nest boxes and the scientific rigour of experimental studies. Oikos 63:309-311

Møller AP (1994) Facts and artefacts in nest box studies: implications for studies of birds of prey. J Raptor Res 28:143-148

Newton I (ed) (1989) Lifetime reproduction in birds. Academic, London

Newton I (1994) The role of nestsites in limiting the numbers of holenesting birds: a review. Biol Conserv 70:265-276

Ontiveros D, Caro J, Pleguezuelos JM (2008) Possible functions of alternative nests in raptors: the case of Bonelli's eagle. J Ornithol 149:253-259

Petty SJ, Shaw G, Anderson DIK (1994) Value of nest boxes for population studies and conservation of owls in coniferous forests in Britain. J Raptor Res 28:134-142

Philips JR, Dindal DL (1977) Raptor nests as a habitat for invertebrates: a review. Raptor Res 11:87-96

Pomarol M (1996) Artificial nest structure design and management implications for the lesser kestrel (Falco naumanni). J Raptor Res 30:169-172

Ravussin P-A, Trolliet D, Willenegger L, Béguin D, Matalon G (2001) Choix du site de nidification chez la chouette de Tengmalm Aegolius funereus: influence des nichoirs. Nos Oiseaux 5:41-51

Riegert J, Fainová D, Bystřická D (2010) Genetic variability, body characteristics and reproductive parameters of neighbouring rural and urban common kestrel (Falco tinnuculus) populations. Pop Ecol 52:73-79

Rohrbaugh RW Jr, Yahner RH (1997) Effects of macrohabitat and microhabitat on nest box use and nesting success of American kestrels. Wilson Bull 109:410-423

Roulin A, Richner H, Ducrest A-L (1998) Genetic, environmental, and condition-dependent effects on female and male ornamentation in the barn owl Tyto alba. Evolution 52:1451-1460

Roulin A, Kölliker M, Richner H (2000) Barn owl (Tyto alba) siblings vocally negotiate resources. Proc R Soc Lond B 267:459-463

Roulin A, Ducrest A-L, Balloux F, Dijkstra C, Riols C (2003) A female melanin ornament signals offspring fluctuating asymmetry in the barn owl. Proc R Soc Lond B 270:167-171

Roulin A, Christe P, Dijkstra C, Ducrest A-L, Jungi TW (2007) Origin-related environmental, sex, and age determinants of immunocompetence, suspectibility to ectoparasites, and disease symptoms in the barn owl. Biol J Linn Soc 90:703-718

Roulin A, Almasi B, Jenni L (2010) Temporal variation in glucocorticoid levels during the resting phase is associated in opposite way with maternal and paternal melanic coloration. J Evol Biol 23:2046-2053

Santolo GM, Yamamoto JT (2009) Nest box and site use by, and selenium concentrations in, American kestrels at Keterson reservoir, Central California. J Raptor Res 43:315-324

Saurola P (2008) Monitoring birds of prey in Finland: a summary of methods, trends, and statistical power. Ambio 37:413-419

Schönn S, Scherzinger W, Exo K-M, Ille R (1991) Der Steinkauz. Neue Brehm-Bücherei 606, Wittenberg Lutherstadt

Smallwood JA, Causey MF, Mossop DH, Klucsarits JR, Robertson B, Robertson S, Mason J, Maurer MJ, Melvin RJ, Dawson RD, Bortolotti GR, Parrish JW Jr, Breen TF, Boyd K (2009) Why are American kestrels (Falco sparverius) populations declining in North America? Evidence from nest box programs. J Raptor Res 43:274-282

Solonen T (1993) Spacing of birds of prey in southern Finland. Ornis Fenn 70:129-143
Sonerud GA (1989) Reduced predation by Pine Martens on nest of Tengmalm's owl in relocated boxes. Anim Behav 37:332-334

Sonerud GA (1993) Reduced predation by nest box relocation: differential effect on Tengmalm's owl nests and artificial nests. Ornis Scand 24:249-253

Steenhof K, Peterson BE (2009) American kestrel reproduction in southwestern Idaho: annual variation and long-term trends. J Raptor Res 43:283-290

Sullivan BL, Kershner EL, Finn SP, Condon AM, Cooper DM, Garcelon DK (2003) Nest-site characteristics and linear abundance of cliff-nesting American kestrels on San Clemente Island, California. J Raptor Res 37:323-329

Sunde P (2005) Predators control post-fledging mortality in tawny owls, Strix aluco. Oikos 110:461-472

Tella JL, Bortolotti GR, Forero MG, Dawson RD (2000) Environmental and genetic variation in T-cell-mediated immune response of fledgling American kestrels. Oecologia 123:453-459

Temple SE (1986) Do predators always capture substandard individuals disproportionately from prey populations? Ecology 68:669-674

Toland BR, Elder WH (1987) Influence of nest box placement and density on abundance and productivity of American kestrels in central Missouri. Wilson Bull 99:712-717

Tomé R, Bloise C, Korpimäki E (2004) Nest-site selection and nesting success of little owls (Athene noctua) in Mediterranean woodland and open habitat. J Raptor Res 38:35-46

Valdez U, Robertson S, Robertson B, Bildstein KL (2000) Nestbox use by American kestrels (Falco sparverius) and European starlings (Sturnus vulgaris) in eastern Pennsylvania. Pennsylvania Birds 14:150-153

Valkama J, Korpimäki E (1999) Nestbox characteristics, habitat quality and reproductive success of Eurasian kestrels. Bird Study 46:81-88

Valkama J, Korpimäki E, Arroyo B, Beja P, Bretagnolle V, Bro E, Kenward R, Mañosa S, Redpath SM, Thirgood S, Viñuela J (2005) Birds of prey as limiting factors of gamebird populations in Europe: a review. Biol Rev 80:171-203

Van Nieuwenhuyse D, Génot J-C, Johnson DH (2008) The little owl. Cambridge University Press, Cambridge

Village A (1983) The role of nest-site availability and territorial behaviour in limiting the breeding density of kestrels. J Anim Ecol 52:635-645

Wendt E (1978) Brutröhre für Steinkäuze. Wir und die Vögel 10/6: 24

Wiebe KL, Slagsvold T (2009) Mouth colouration in nestling birds: increasing detection or signaling quality? Anim Behav 78:1413-1420

Wiehn J, Korpimäki E (1997) Food limitation on brood size: experimental evidence in the Eurasian kestrel. Ecology 78:2043-2050

Wiehn J, Korpimäki E (1998) Resource levels, reproduction and resistance to haematozoan infections. Proc R Soc Lond B 265:1197-1201

Wimberger PH (1984) The use of green plant material in bird nests to avoid ectoparasites. Auk 101:615-618

Zingg S, Arlettaz R, Schaub M (2010) Nest box design influences territory occupancy and reproduction in a declining, secondary cavity-nesting bird. Ardea 98:67-75

Zuur AF, Ieno EN, Elphick CS (2010) A protocol for data exploration to avoid common statistical problems. Methods Ecol Evol $1: 3-14$ 